\title{
DISTRIBUIÇÃO DE FÓSFORO NO BULBO MOLHADO, APLICADO VIA FERTIRRIGAÇÃO POR GOTEJAMENTO COM ÁCIDO FOSFÓRICO ${ }^{1}$
}

\author{
JOSÉ R. ZANINI ${ }^{2}$, ANA K. G. BARRETO ${ }^{3}$, LETICIA C. FORATTO ${ }^{4}$, \\ WILLIAM NATALE ${ }^{5}$
}

\begin{abstract}
RESUMO: Foram investigados a distribuição do fósforo, o $\mathrm{pH}$ e a umidade do solo no bulbo molhado em um Latossolo sem vegetação, após fertirrigação com ácido fosfórico, durante 21 dias. $\mathrm{O}$ experimento foi instalado na UNESP/Jaboticabal - SP, em blocos casualizados, com cinco repetições. Os tratamentos foram $0 ; 30 ; 60 ; 90$ e $120 \mathrm{~kg} \mathrm{ha}^{-1}$ de $\mathrm{P}_{2} \mathrm{O}_{5}$, dividindo-se as doses em quatro aplicações semanais, via fertirrigação. Após a última aplicação, foram abertas trincheiras nos bulbos molhados e coletadas amostras de solo em quadrículas de $100 \mathrm{~cm}^{2}$. O ácido fosfórico provocou aumento da acidez e elevados teores de fósforo no bulbo, principalmente até $30 \mathrm{~cm}$ de distância lateral e até $40 \mathrm{~cm}$ de profundidade, em relação ao ponto de gotejamento. $\mathrm{O}$ aumento da dose de ácido fosfórico (90 e $120 \mathrm{~kg} \mathrm{ha}^{-1}$ de $\mathrm{P}_{2} \mathrm{O}_{5}$ ) provocou maiores teores de fósforo e maior acidificação do solo até $30 \mathrm{~cm}$ de distância lateral e até $40 \mathrm{~cm}$ de profundidade. A distribuição do fósforo e seu efeito no $\mathrm{pH}$ no volume de solo molhado não seguiram a distribuição de umidade no mesmo.
\end{abstract}

PALAVRAS-CHAVE: bulbo úmido, irrigação por gotejamento, acidez do solo.

\section{PHOSPHOROUS DISTRIBUTION IN THE DRIP BULB, APPLIED BY FERTIGATION WITH PHOSPHORIC ACID}

\begin{abstract}
The phosphorous distribution, $\mathrm{pH}$ and the water content in the wet bulb of a Latosol without vegetation fertigated along one month, were investigated. The experiment, with randomised blocks design was carried out in UNESP - São Paulo State University, Jaboticabal Brazil. The treatments $\left(0 ; 30 ; 60 ; 90\right.$ and $120 \mathrm{~kg} \mathrm{ha}^{-1}$ of $\left.\mathrm{P}_{2} \mathrm{O}_{5}\right)$ were divided in four weekly applications, by fertigation, using phosphoric acid. After the last application, trenches in the bulbs were opened, and samples of the soil were collected in $100 \mathrm{~cm}^{2}$ areas. The phosphoric acid increased the acidity and provoked high phosphorus contents in the fertigated bulbs, until $30 \mathrm{~cm}$ of lateral distance and until $40 \mathrm{~cm}$ of depth, in relation to the drip point. Increasing the rate of the phosphoric acid (90 and $120 \mathrm{~kg} \mathrm{ha}^{-1}$ of $\mathrm{P}_{2} \mathrm{O}_{5}$ ) resulted in higher phosphorus concentration and soil acidity until $30 \mathrm{~cm}$ of lateral distance and until $40 \mathrm{~cm}$ of depth. The phosphorous distribution and its effect in the $\mathrm{pH}$ did not follow the moisture distribution in the bulb.
\end{abstract}

KEYWORDS: wet bulb, trickle irrigation, soil acidity.

\section{INTRODUÇÃO}

Nos últimos anos, além da forma tradicional de aplicação de nutrientes, tem sido adotada a fertirrigação, pois permite a aplicação de fertilizantes simultaneamente com a água de irrigação (ELOI et al., 2004). Comparada com outros sistemas de fornecimento de fertilizantes às plantas, a fertirrigação melhora a eficiência do uso dos fertilizantes, reduzindo perdas dos nutrientes no solo e economizando mão-de-obra e energia (CABELLO, 1990); para isso, os sistemas precisam ser bem projetados e manejados (SOUZA \& BOTREL, 2005).

\footnotetext{
${ }^{1}$ Extraído da dissertação de mestrado do segundo autor

${ }^{2}$ Eng $^{\mathrm{o}}$ Agrônomo, Prof. Doutor, Depto de Engenharia Rural, UNESP, Jaboticabal - SP: jrzanini @ fcav.unesp.br

${ }^{3}$ Eng $^{\mathrm{o}}$ Agrônoma, Mestre em Ciência do Solo pela UNESP, Jaboticabal - SP

${ }^{4}$ Eng $^{\mathrm{a}}$ Agrônoma graduada pela UNESP, Jaboticabal - SP, lety_foratto@yahoo.com

${ }^{5}$ Eng ${ }^{0}$ Agrônomo, Prof. Adjunto, Departamento de Solos e Nutrição de Plantas, UNESP, Jaboticabal - SP

Recebido pelo Conselho Editorial em: $1^{\circ}-8-2005$

Aprovado pelo Conselho Editorial em: 20-4-2007
} 
A maior disponibilidade de fósforo no solo aumentou a produtividade do melão, e os maiores valores de $\mathrm{pH}$ do solo melhoraram a qualidade dos frutos (MIRANDA et al., 2006). A irrigação e a fertirrigação são importantes no desenvolvimento de culturas, na produtividade e na qualidade do produto (BAR-YOSEF, 1999).

A fertirrigação por gotejamento aumenta a distribuição de fósforo no solo, pois provoca maior concentração em uma faixa estreita, saturando os sítios de fixação próximos ao ponto de aplicação. A textura, a taxa de aplicação e a quantidade de água aplicada são as variáveis que mais afetam seu movimento no solo (VILLAS BÔAS et al., 2002). O movimento do fósforo no solo difere conforme a textura do mesmo (GUSTAFSON, 1974), o pH do fertilizante aplicado (PAPADOPOULOS, 1999) e o pH do solo (ARGO \& BIERNBAUM, 1996). O pH ideal para que o fósforo fique solúvel no solo é 6,5, mas é aceitável a faixa de 6,2 a 6,8, na qual ocorre maior disponibilidade de nutrientes (BURT et al., 1995). Segundo COTE et al. (2003), o conhecimento das propriedades do solo permite planejar a implantação e as estratégias de manejo da fertirrigação. A aplicação de água, o transporte dos nutrientes, a distribuição de raízes, o local de instalação dos emissores, além das doses aplicadas e sua freqüência resultarão em aumento da produtividade e em redução de impactos negativos da irrigação, quando bem planejados.

A colocação de adubos na região das raízes e o fracionamento das doses possibilitam aumentar a eficiência das adubações (BURT et al., 1995). Segundo LUDWICK (2002), a fertirrigação pode ser altamente útil em fases que requerem grandes quantidades de nutrientes (floração, enchimento de grãos, mobilização de açúcares) ou quando o solo fixa grandes quantidades de fósforo e potássio.

Segundo LAMM \& TROOIEN (2003), há novas pesquisas sendo realizadas para otimizar as alocações de água, sementes e nutrientes, levando-se em consideração a utilização de outros produtos químicos, minimizando o impacto poluente dos mesmos e a viabilidade econômica da adoção do sistema, bem como a relação de longevidade dos materiais, mão-de-obra e produtividade.

A quantidade de nutrientes aplicados é importante, sendo a fertirrigação mais eficiente que a adubação convencional (MIRANDA et al., 2006). Em cana-de-açúcar, permite reduzir a dose de nitrogênio, apresentando vantagens sobre as aplicações convencionais, devido à redução das perdas por volatilização e desnitrificação (THORBURN et al., 2003).

Devido à pouca mobilidade de fósforo no solo, não se recomenda a sua aplicação na superfície do mesmo, com irrigação por aspersão. Entretanto, a irrigação localizada é uma exceção quanto a esse aspecto (RAUSCHKOLB et al., 1986). LOGAN \& MCLEAN (1973) demonstraram que é possível obter maior movimento do fósforo, utilizando altas doses de fertilização fosfatada.

A aplicação de fósforo via fertirrigação, com irrigação localizada, utilizando adubos comumente empregados em outras formas de aplicação, tais como o superfosfato simples ou o monofosfato de amônio, pode causar obstrução de emissores e incrustações nas canalizações, principalmente quando a água é alcalina. Para evitar esse problema, pode ser utilizado o ácido fosfórico como fonte de fósforo, porém existe a necessidade de pesquisar sua distribuição no bulbo molhado e seu efeito no $\mathrm{pH}$ do solo. O ácido fosfórico tem sido amplamente utilizado nos últimos anos, principalmente na fertirrigação por microaspersão e por gotejamento (PAPADOPOULOS, 1999).

A irrigação localizada é a mais apropriada para a fertirrigação, pois permite manter na zona limitada do solo disponível às raízes, umidade satisfatória e concentração ótima de nutrientes para o desenvolvimento da cultura (VILLAS BÔAS et al., 2002), satisfazendo pontualmente suas necessidades, conforme seu estágio de desenvolvimento (LI et al., 2003).

BAR-YOSEF \& SHEIKHOLSMI (1976) avaliaram o movimento da água e do íon fosfato no solo. O fósforo aplicado em solo argiloso, depois de uma e de três irrigações, atingiu 4 e $6 \mathrm{~cm}$ abaixo da superfície do solo, respectivamente. Nos solos arenosos, o alcance do íon fosfato foi duas 
vezes maior na direção horizontal e três vezes na direção vertical, comparada à mesma quantidade aplicada nos solos argilosos, com irrigação por gotejamento. Estudando o movimento do fósforo no solo, VIVANCOS (1993) observou alcance de até $50 \mathrm{~cm}$ de profundidade, porém na faixa de 20$30 \mathrm{~cm}$ ocorreram maiores concentrações, tanto na vertical, quanto na horizontal.

SILVA \& MAROUELLI (2001) relatam que o ácido fosfórico utilizado como fertilizante tem a vantagem de reduzir o $\mathrm{pH}$ da água, reduzindo o risco de precipitação de carbonatos e entupimentos dos emissores, além de ser indicado para gotejamento subterrâneo, evitando intrusão de raízes nos gotejadores. Entretanto, VILLAS BÔAS et al. (1999) atentam para possíveis problemas de corrosão que o ácido fosfórico poderá ocasionar em peças metálicas dos sistemas de irrigação.

ZANINI (1991) estudou a distribuição de água no mesmo solo da presente pesquisa. Utilizando gotejamento com $3 \mathrm{~L} \mathrm{~h}^{-1}$, após cinco aplicações com intervalos semanais, totalizando $70,5 \mathrm{~L}$, verificou que a umidade máxima atingida no bulbo molhado foi de $30 \%$; a máxima expansão lateral da água foi de $70 \mathrm{~cm}$, e a profundidade máxima esteve na faixa de 90 a $100 \mathrm{~cm}$; os maiores valores de umidade concentraram-se na região central do bulbo, concordando com BOTREL (1988).

Partindo-se da hipótese de que o aumento da dose de fósforo amplia sua distribuição no solo, devido à saturação da sua capacidade de adsorção, neste trabalho, foi estudado, no bulbo molhado, o efeito da fertirrigação por gotejamento com ácido fosfórico na distribuição do fósforo e no $\mathrm{pH}$ de um Latossolo desprovido de vegetação.

\section{MATERIAL E MÉTODOS}

O experimento foi conduzido em área da UNESP/Jaboticabal - SP, com declividade média de 8\%. O solo corresponde ao Latossolo Vermelho eutroférrico (EMBRAPA, 1999), cujos resultados da análise física se encontram na Tabela 1.

TABELA 1. Valores de análise física do solo da área experimental.

\begin{tabular}{cccc}
\hline Profundidade $(\mathrm{cm})$ & Argila $(\%)$ & Silte $(\%)$ & Areia $(\%)$ \\
\hline $0-20$ & 66 & 15 & 19 \\
$20-30$ & 58 & 22 & 19 \\
$30-40$ & 63 & 19 & 18 \\
\hline
\end{tabular}

Anteriormente à aplicação dos tratamentos, foi utilizado herbicida para combater plantas invasoras e realizadas duas gradagens para o destorroamento e regularização da superfície do solo. Nessa época, foram coletadas amostras de solo para determinações das características químicas (Tabela 2).

TABELA 2. Resultados de análises químicas do solo da área experimental (maio de 2003).

\begin{tabular}{|c|c|c|c|c|c|c|c|c|c|c|}
\hline \multirow{2}{*}{$\begin{array}{l}\text { Profundidade } \\
(\mathrm{cm})\end{array}$} & \multirow{2}{*}{$\begin{array}{c}\mathrm{pH} \\
\left(\mathrm{CaCl}_{2}\right)\end{array}$} & \multirow{2}{*}{$\begin{array}{c}\text { M.O. } \\
\left(\mathrm{g} \mathrm{dm}^{-3}\right)\end{array}$} & \multirow{2}{*}{$\begin{array}{c}\text { P resina } \\
\left(\mathrm{mg} \mathrm{dm}^{-3}\right)\end{array}$} & $\mathrm{K}$ & $\mathrm{Ca}$ & $\mathrm{Mg}$ & $\mathrm{H}+\mathrm{A}$ & SB & $\mathrm{T}$ & \multirow{2}{*}{$\begin{array}{c}\mathrm{V} \\
(\%)\end{array}$} \\
\hline & & & & \multicolumn{6}{|c|}{$\mathrm{mmol}_{\mathrm{c}} \mathrm{dm}^{-3}$} & \\
\hline $0-20$ & 4,9 & 25 & 19 & 2,6 & 22 & 12 & 38 & 36,6 & 74,6 & 49 \\
\hline $20-40$ & 5,0 & 20 & 07 & 0,8 & 20 & 11 & 38 & 31,8 & 69,8 & 46 \\
\hline $40-60$ & 4,9 & 16 & 03 & 0,4 & 19 & 10 & 34 & 29,4 & 63,4 & 46 \\
\hline $60-80$ & 5,3 & 14 & 03 & 0,2 & 18 & 10 & 22 & 28,2 & 50,2 & 56 \\
\hline $80-100$ & 5,2 & 11 & 03 & 0,1 & 17 & 06 & 20 & 23,1 & 43,1 & 54 \\
\hline
\end{tabular}

O experimento teve início em 19 de agosto de 2003 e constou de cinco tratamentos e cinco repetições, correspondendo a 25 pontos de gotejamento (25 parcelas), conforme Figura 1. 
1-Conjunto motobomba

2-Reservatório

3-Filtro de areia

4-Filtro de discos

5-Registro de esfera

6-Manômetro

7-Tanque de fertilizante

8-Gotejador

9-Linha de gotejadores

10-Tubo de descarga $\triangle$ Dose 0 (Testemunha)

$\square$ Dose 1

Dose 2

Dose 3

$\checkmark$
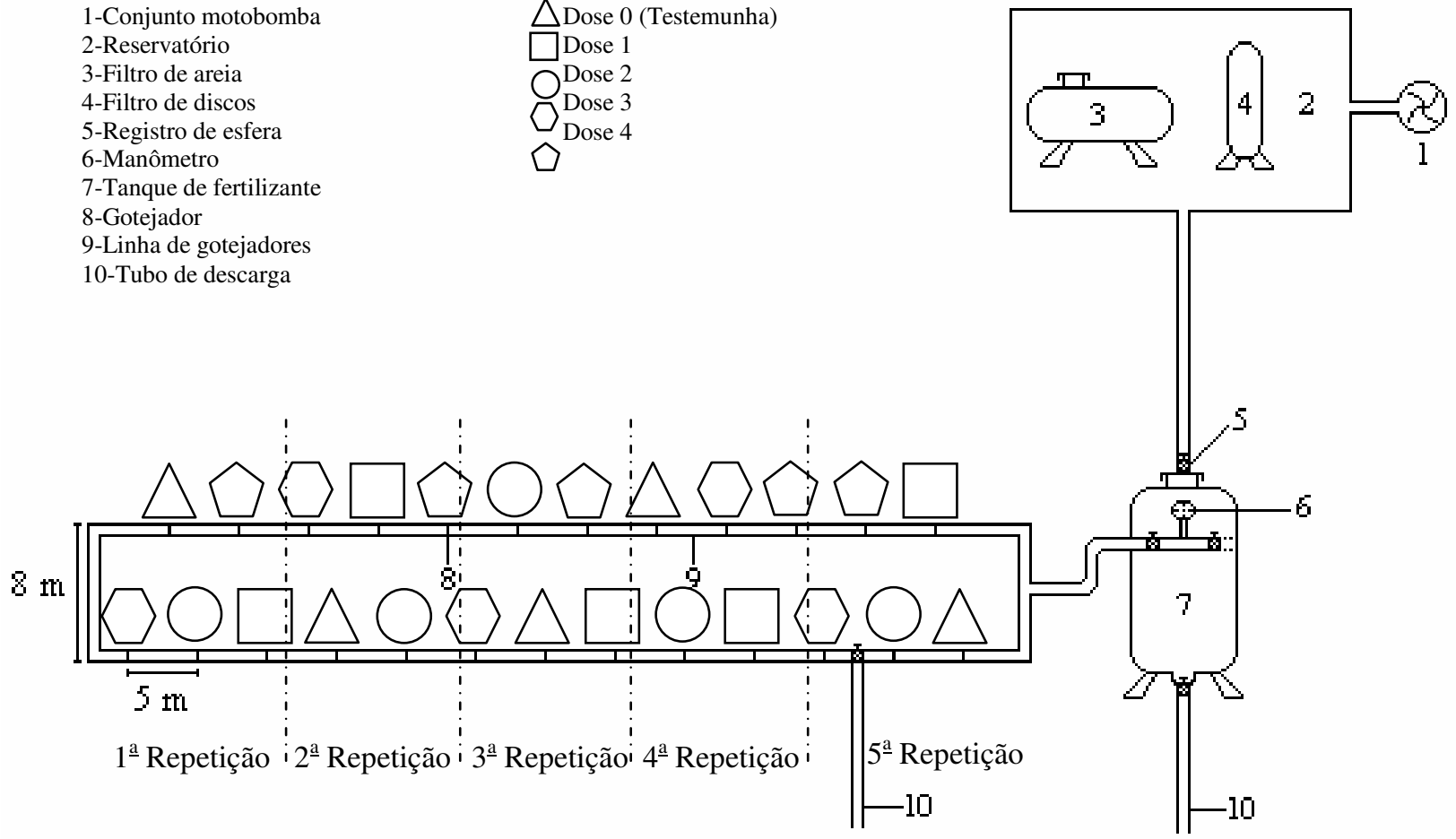

FIGURA 1. Esquema do experimento no campo, com distribuição dos tratamentos e componentes do sistema de fertirrigação.

Os tratamentos foram constituídos por quatro doses de ácido fosfórico (densidade = $1,66 \mathrm{~kg} \mathrm{dm}^{-3} ; \mathrm{P}_{2} \mathrm{O}_{5}=52 \%$ ) aplicadas via irrigação e um tratamento que utilizava somente água (testemunha): 0; 30; 60; 90 e $120 \mathrm{~kg} \mathrm{ha}^{-1}$ de $\mathrm{P}_{2} \mathrm{O}_{5}$. As doses foram divididas em quatro aplicações, com intervalos semanais.

Procurando-se obter bulbo de molhamento com profundidade de aproximadamente $80 \mathrm{~cm}$, baseando-se em ZANINI (1991), em cada aplicação, as parcelas receberam 20 L de água ou da mistura de água e ácido fosfórico, totalizando $80 \mathrm{~L}$ após as quatro aplicações.

Para a realização das fertirrigações, foi utilizado tanque de derivação de fluxo, e o tempo de aplicação foi calculado com a equação que descreve a concentração no mesmo (FAO, 1986):

$$
\mathrm{C}_{\mathrm{t}}=\mathrm{C}_{0} \mathrm{e}^{-\mathrm{x}}
$$

em que,

$\mathrm{C}_{\mathrm{t}}$ - concentração da solução no tanque após o tempo t;

$\mathrm{C}_{0}$ - concentração inicial da solução no tanque, e

e - base do logaritmo neperiano.

Nessa equação, $x$ é a relação entre o volume que passou pelo tanque até o tempo t e o volume do tanque $(70 \mathrm{~L})$.

Para a linha de gotejamento, foi utilizado tubo de polietileno de $12 \mathrm{~mm}$, ao qual foram conectados microtubos de polietileno de $4 \mathrm{~mm}$ de diâmetro e $40 \mathrm{~cm}$ de comprimento; nas extremidades dos microtubos, foram acoplados gotejadores modelo KATIF, com compensador de pressão e vazão de $3,75 \mathrm{~L} \mathrm{~h}^{-1}$. O manejo do sistema foi realizado com registros de manobra rápida na entrada e na saída do circuito da linha de gotejadores e no tanque de fertilizante, possibilitando a realização das irrigações e fertirrigações.

As fertirrigações foram realizadas semanalmente (1 $1^{\mathrm{a}}: 25-8 ; 2^{\mathrm{a}}: 1^{\underline{\mathrm{o}}}-9 ; 3^{\mathrm{a}}: 8-9$ e $\left.4^{\mathrm{a}}: 15-9\right)$, iniciando-as às $8 \mathrm{~h}$. Em cada aplicação, o tanque recebia aproximadamente $40 \mathrm{~L}$ de água e a quantidade total de ácido $(1.385 \mathrm{~mL})$ necessária para todos os tratamentos; em seguida, 
homogeneizava-se a solução, completando-se o volume do tanque e fechava-se o mesmo. Antes de iniciar a aplicação, os microtubos dos tratamentos $\left(T_{1}, T_{2}, T_{3}, T_{4}\right)$ eram abertos, com exceção do tratamento $\mathrm{T}_{0}$. Decorrido o tempo necessário para a aplicação de ácido a cada tratamento, os microtubos dos gotejadores eram fechados, estrangulando-os rapidamente para a interrupção do gotejamento simultaneamente a todas as parcelas de um mesmo tratamento.

Após as aplicações dos tratamentos que recebiam ácido, os gotejadores eram fechados, e a linha e o tanque eram lavados. Em seguida, procedia-se à aplicação do tratamento $\mathrm{T}_{0}$, que recebia somente água, aplicando-se também o volume de água aos demais tratamentos, para completar $20 \mathrm{~L}$.

Seguindo procedimento apresentado por ZANINI (1991), um dia após a quarta fertirrigação, nos bulbos molhados, foram abertas trincheiras com retroescavadeira e preparou-se um plano vertical com uma pá reta, passando pelo ponto de gotejamento, possibilitando identificar visualmente a conformação do bulbo molhado (Figura 2). Nesse plano, foram demarcadas quadrículas de $100 \mathrm{~cm}^{2}$ e coletadas amostras de solo de aproximadamente 0,5 $\mathrm{kg}$, para determinação de umidade, $\mathrm{pH}$ e fósforo. Distante de $2 \mathrm{~m}$ do bulbo, no mesmo plano vertical das trincheiras, foram coletadas amostras de uma coluna de quadrículas, para a realização das mesmas análises das amostras do interior do bulbo.

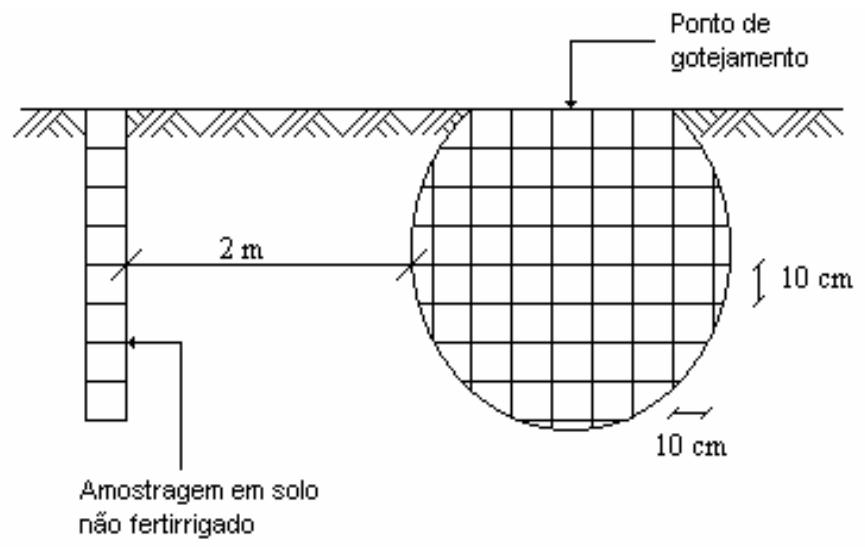

FIGURA 2. Esquema de demarcação das quadrículas para retirar amostras de solo nas trincheiras. Fonte: ZANINI (1991).

As repetições de amostras dos tratamentos, correspondentes à mesma posição nos bulbos, foram juntadas, originando amostras compostas e enviadas ao laboratório para determinação de umidade (método gravimétrico), $\mathrm{pH}$ em cloreto de cálcio (leitura em peagômetro) e fósforo (método da resina). Tendo-se constatado nas primeiras análises que o ácido não atingiu todas as regiões do bulbo, as análises de $\mathrm{pH}$ e de fósforo foram realizadas até $40 \mathrm{~cm}$ de profundidade e até $30 \mathrm{~cm}$ de raio (expansão lateral), em relação ao ponto de gotejamento.

\section{RESULTADOS E DISCUSSÃO}

\section{pH do solo}

Na Figura 3, verifica-se que o tratamento $\mathrm{T}_{0}$ apresentou valores médios de $\mathrm{pH}$ semelhantes aos apresentados pela referência, estando os maiores valores de $\mathrm{pH}$ nas camadas mais superficiais do solo, pois não houve aplicação de ácido fosfórico com o gotejamento.

Para o tratamento $\mathrm{T}_{1}$ (Figura 4), verifica-se que o $\mathrm{pH}$ do solo no bulbo molhado foi reduzido pela aplicação de ácido fosfórico. Porém, o efeito do ácido fosfórico no $\mathrm{pH}$ do solo foi maior ao redor do gotejador, na faixa de apenas 10 a $20 \mathrm{~cm}$ de raio e até $30 \mathrm{~cm}$ de profundidade. 


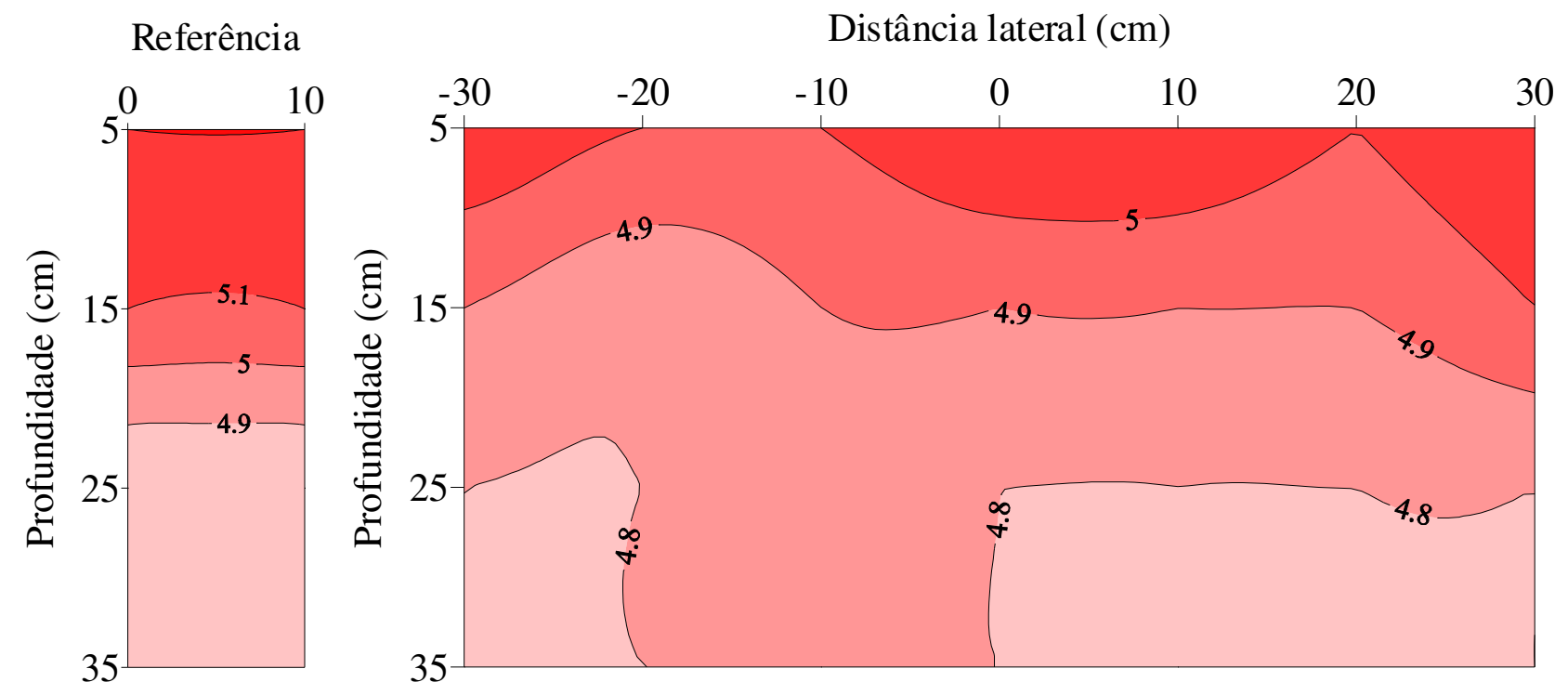

FIGURA 3. Distribuição de $\mathrm{pH}$ no solo sem a adição de ácido fosfórico $\left(\mathrm{T}_{0}\right)$ e na coluna de referência.

Os valores de $\mathrm{pH}$ para o tratamento $\mathrm{T}_{1}$ diferem do apresentado para o tratamento $\mathrm{T}_{0}$, ou seja, apresentam acentuada redução do $\mathrm{pH}$ na região central do bulbo devido ao efeito do ácido fosfórico. Comparando o tratamento $\mathrm{T}_{1}$ com a sua referência, verifica-se grande redução do $\mathrm{pH}$, atingindo 4,1 na camada de 0 a $15 \mathrm{~cm}$ e 4,4 na profundidade de $30 \mathrm{~cm}$. A partir dessa faixa de profundidade, não houve efeito do ácido fosfórico na acidificação do solo.
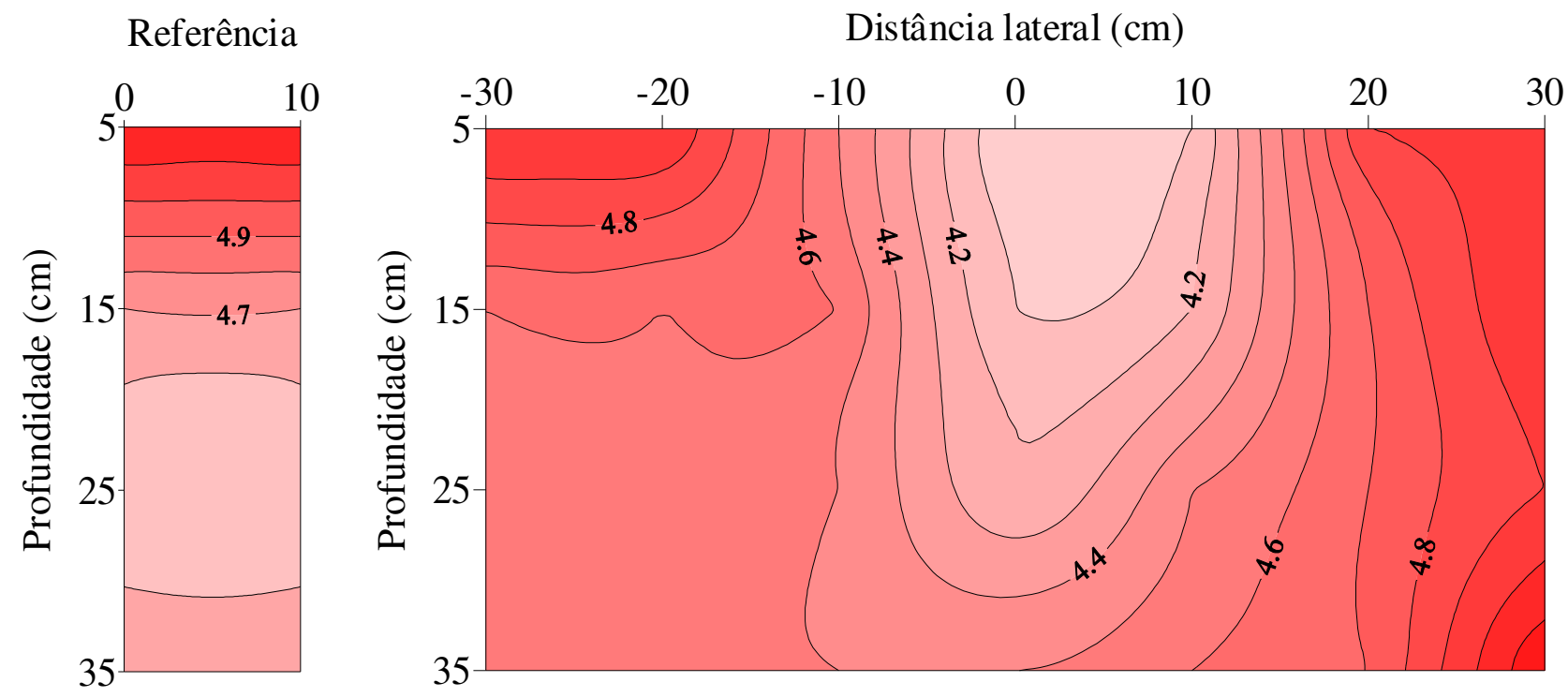

FIGURA 4. Distribuição de pH no solo com a adição de $30 \mathrm{~kg} \mathrm{ha}^{-1}$ de $\mathrm{P}_{2} \mathrm{O}_{5}\left(\mathrm{~T}_{1}\right)$ e na coluna de referência.

Os tratamentos 2; 3 e 4 (Figuras 5; 6 e 7) apresentam comportamentos semelhantes entre si, havendo queda acentuada nos valores de $\mathrm{pH}$ em relação aos valores da referência. Na posição do gotejador $(0 \mathrm{~cm})$, sempre ocorreram os menores valores de $\mathrm{pH}$, chegando a atingir 3,8 . 

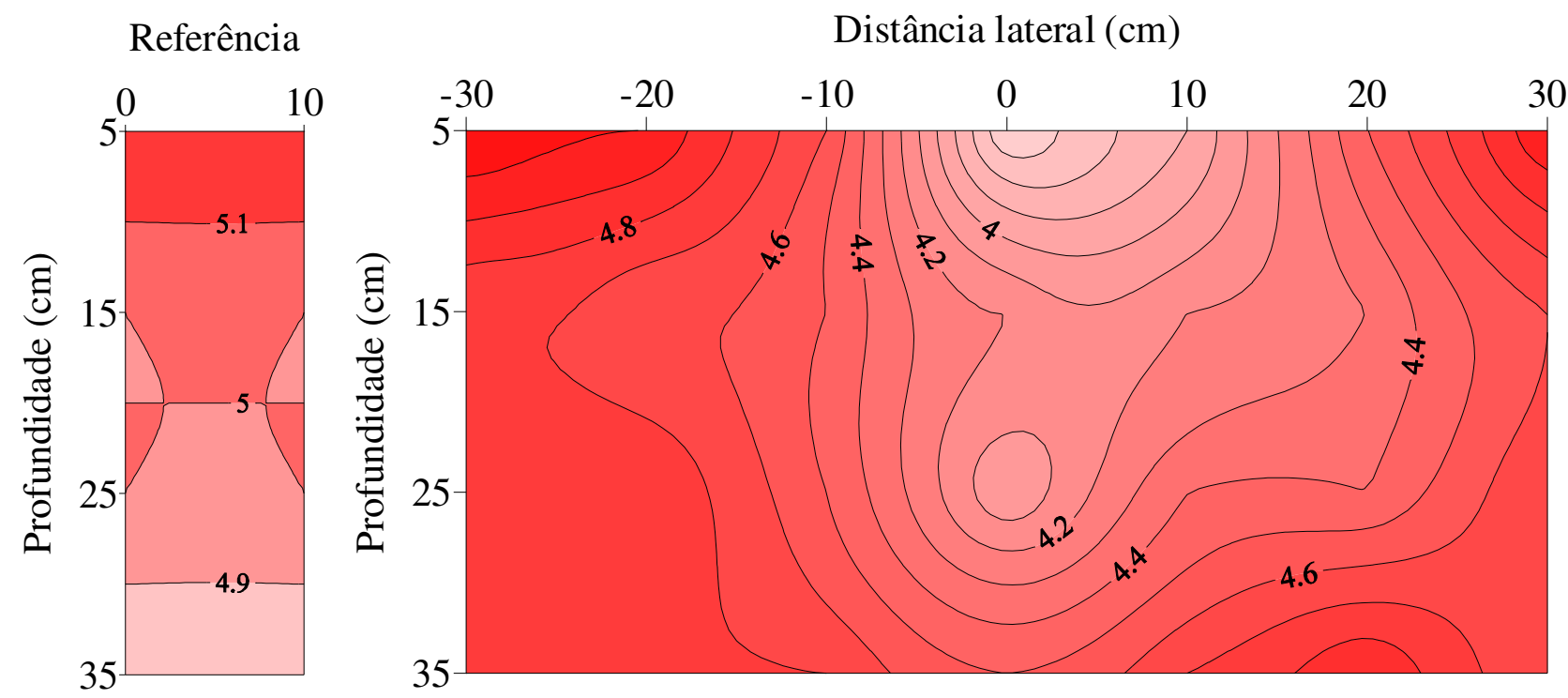

FIGURA 5. Distribuição de pH no solo com a adição de $60 \mathrm{~kg} \mathrm{ha}^{-1}$ de $\mathrm{P}_{2} \mathrm{O}_{5}\left(\mathrm{~T}_{2}\right)$ e na coluna de referência.

Comparando-se a referência e o tratamento $\mathrm{T}_{2}$ (Figura 5), pode-se observar que, após a aplicação do ácido, os valores de pH baixaram para todas as camadas analisadas, até $30-40 \mathrm{~cm}$. Comparando-se $\mathrm{T}_{2}$ com $\mathrm{T}_{1}$, verificam-se maiores variações de $\mathrm{pH}$ para o tratamento $\mathrm{T}_{2}$ em relação à referência, atingindo maior profundidade no bulbo molhado. Esses comportamentos revelam efeito do aumento da dose de ácido fosfórico quando se mudou do tratamento $\mathrm{T}_{1}$ para o tratamento $\mathrm{T}_{2}$.

Para $\mathrm{T}_{4}$ (Figura 7), verifica-se o mesmo comportamento de $\mathrm{T}_{2}$ e $\mathrm{T}_{3}$ em comparação com a referência. Em todas as profundidades, houve nítido rebaixamento do $\mathrm{pH}$ do solo, com redução de 1,3 até 0,4 no valor de $\mathrm{pH}$, desde a camada de $0-10 \mathrm{~cm}$ até $30-40 \mathrm{~cm}$.

Ainda pelas Figuras 4 a 7, de modo geral, verifica-se que a ação do ácido no rebaixamento do $\mathrm{pH}$ do solo foi mais pronunciada até a faixa de 10 a $20 \mathrm{~cm}$ de distância lateral. Observa-se, também, que a redução do $\mathrm{pH}$ aumentou com o aumento das doses do ácido, demonstrando diferenças entre os efeitos dos tratamentos. Há, também, tendência de maior redução à direita do ponto de gotejamento, refletindo o efeito da declividade do solo no fluxo da solução aplicada em sua superfície.

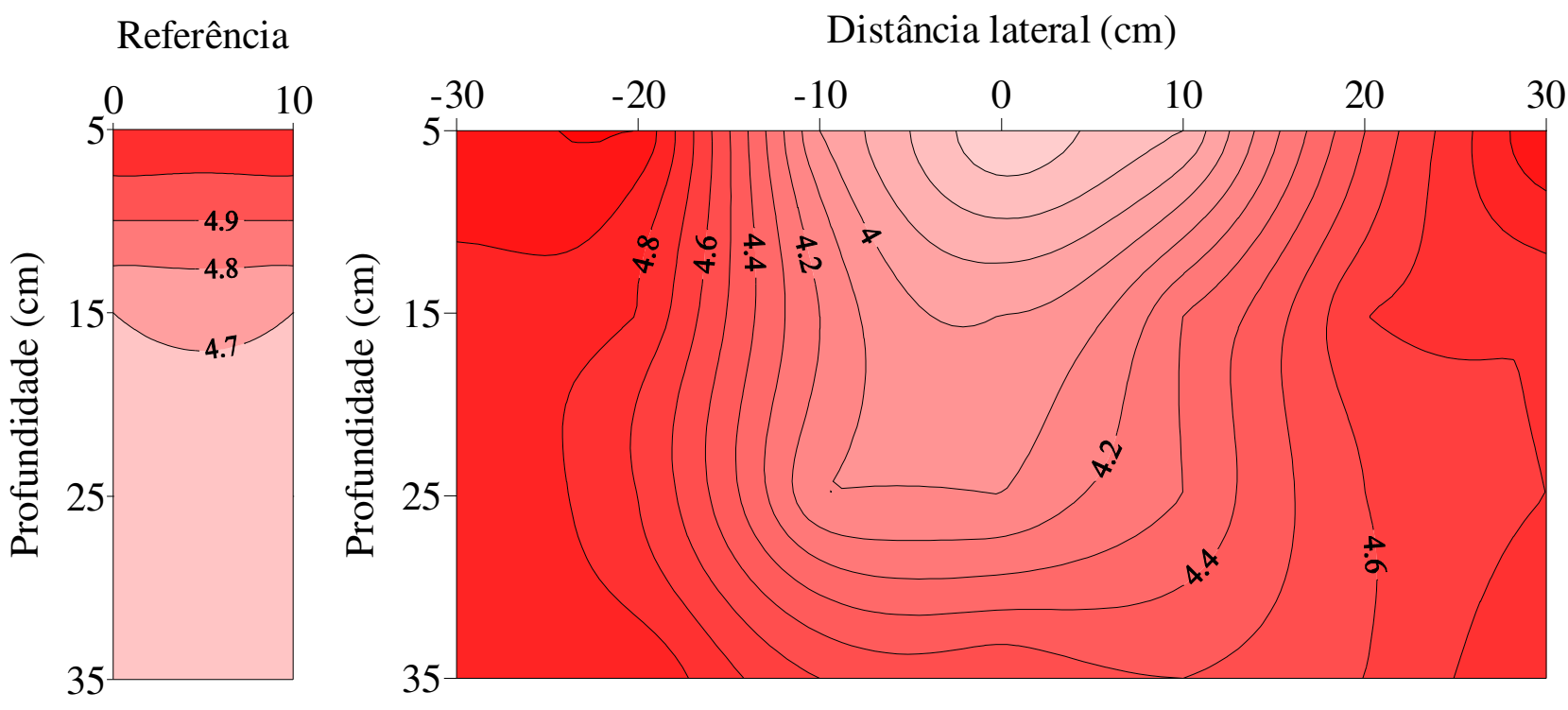

FIGURA 6. Distribuição de pH no solo com a adição de $90 \mathrm{~kg} \mathrm{ha}^{-1}$ de $\mathrm{P}_{2} \mathrm{O}_{5}\left(\mathrm{~T}_{3}\right)$ e na coluna de referência. 

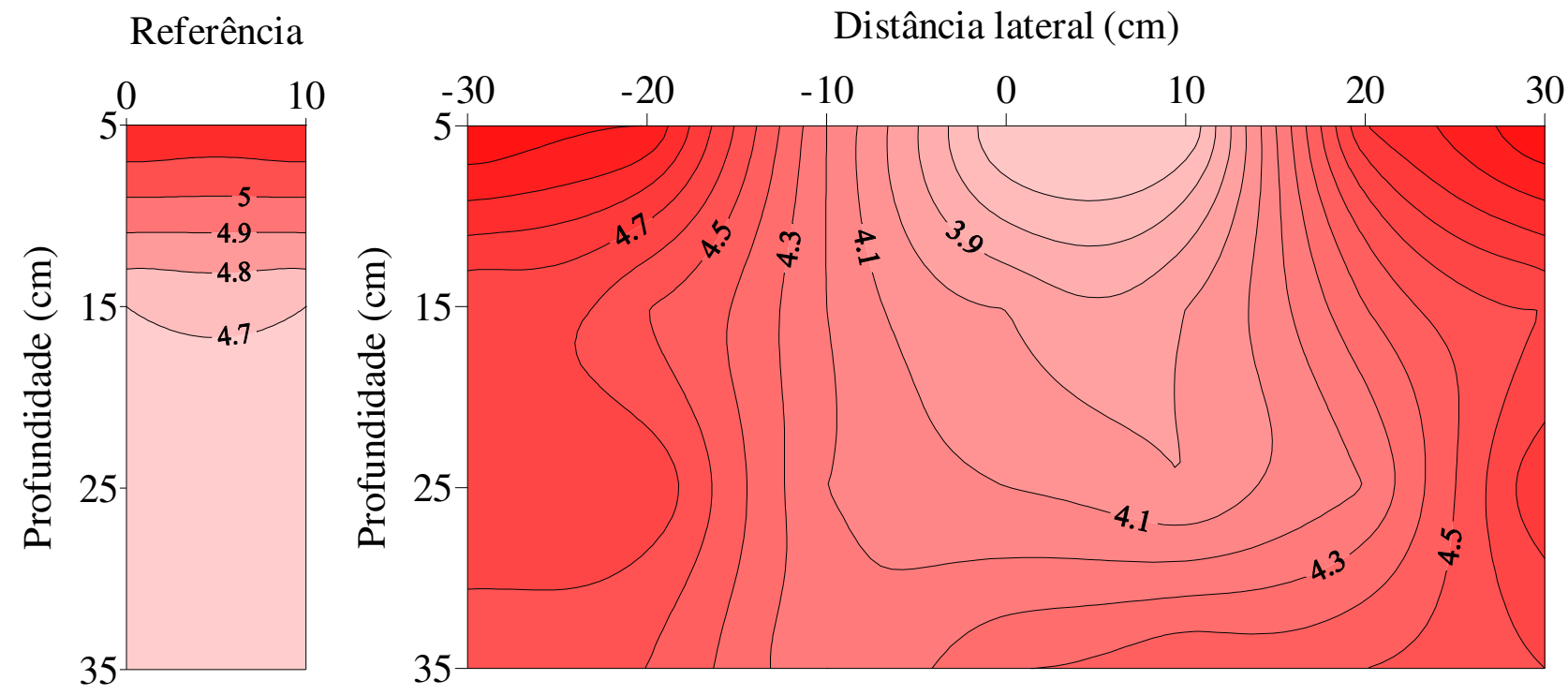

FIGURA 7. Distribuição de pH no solo com a adição de $120 \mathrm{~kg} \mathrm{ha}^{-1}$ de $\mathrm{P}_{2} \mathrm{O}_{5}\left(\mathrm{~T}_{4}\right)$ e na coluna de referência.

\section{Teor de fósforo no solo}

Na Figura 8, comparando-se os valores do tratamento $\mathrm{T}_{0} \mathrm{e}$ os valores da referência, verificase que ambos tiveram o mesmo comportamento, ou seja, os teores são semelhantes e decrescentes com a profundidade do solo. Isso pode ser explicado pela utilização da dose 0 de fósforo para $o$ tratamento $\mathrm{T}_{0}$. Os valores para a referência estão bem próximos dos valores do tratamento $\mathrm{T}_{0}$, e concordam com os valores revelados pela análise do solo no início do experimento (Tabela 2), pois nessas duas situações não houve aplicação de fósforo.
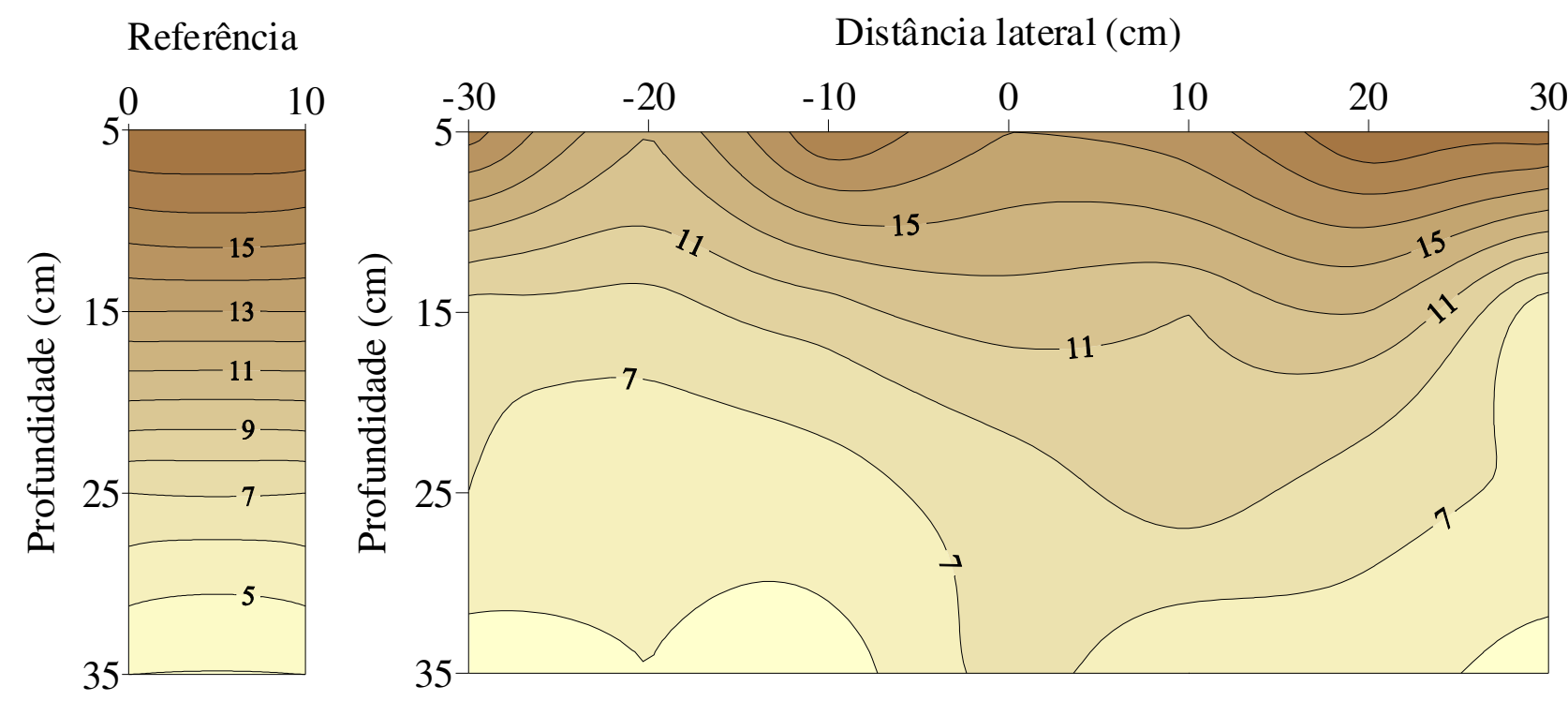

FIGURA 8. Distribuição de fósforo (P: $\mathrm{mg} \mathrm{dm}^{-3}$ ) no perfil do solo sem adição de ácido fosfórico $\left(\mathrm{T}_{0}\right)$ e na coluna de referência.

Para o tratamento $\mathrm{T}_{1}$ (Figura 9), pode-se observar que a maior quantidade de fósforo é encontrada no ponto de gotejamento, decrescendo à medida que se afasta desse ponto até $30 \mathrm{~cm}$ de raio, onde o teor de fósforo é praticamente igual ao teor natural do solo. Assim, a expansão lateral do fósforo ao redor do gotejador atingiu $30 \mathrm{~cm}$ de raio, coincidindo com o raio em que houve efeito no $\mathrm{pH}$ do solo. 
Os tratamentos $\mathrm{T}_{1}$ e $\mathrm{T}_{2}$ (Figuras 9 e 10) apresentam o mesmo comportamento, revelando grandes incrementos de fósforo do solo, até a camada de 30 a $40 \mathrm{~cm}$ de profundidade, devido às doses aplicadas de ácido fosfórico. Para $\mathrm{T}_{3}$ e $\mathrm{T}_{4}$ (Figuras 11 e 12), observa-se o mesmo comportamento de $\mathrm{T}_{1}$ e $\mathrm{T}_{2}$, revelando altíssimos acréscimos do teor de fósforo no bulbo molhado. Quanto maior a dose, maior foi o incremento de fósforo no solo. Com as maiores doses $\left(\mathrm{T}_{3}=\right.$ $90 \mathrm{~kg} \mathrm{ha}^{-1} \mathrm{e} \mathrm{T}_{4}=120 \mathrm{~kg} \mathrm{ha}^{-1}$ ) nas camadas mais profundas (30 a $\left.40 \mathrm{~cm}\right)$, os teores de fósforo foram maiores do que os apresentados para as menores doses $\left(\mathrm{T}_{1}=30 \mathrm{~kg} \mathrm{ha}^{-1} \mathrm{e} \mathrm{T}_{2}=60 \mathrm{~kg} \mathrm{ha}^{-1}\right)$. Assim, o efeito da saturação dos sítios de adsorção do solo provocou maior caminhamento do fósforo, concordando com as informações de COELHO (1994), LUDWICK (2002) e VILLAS BÔAS et al. (2002).

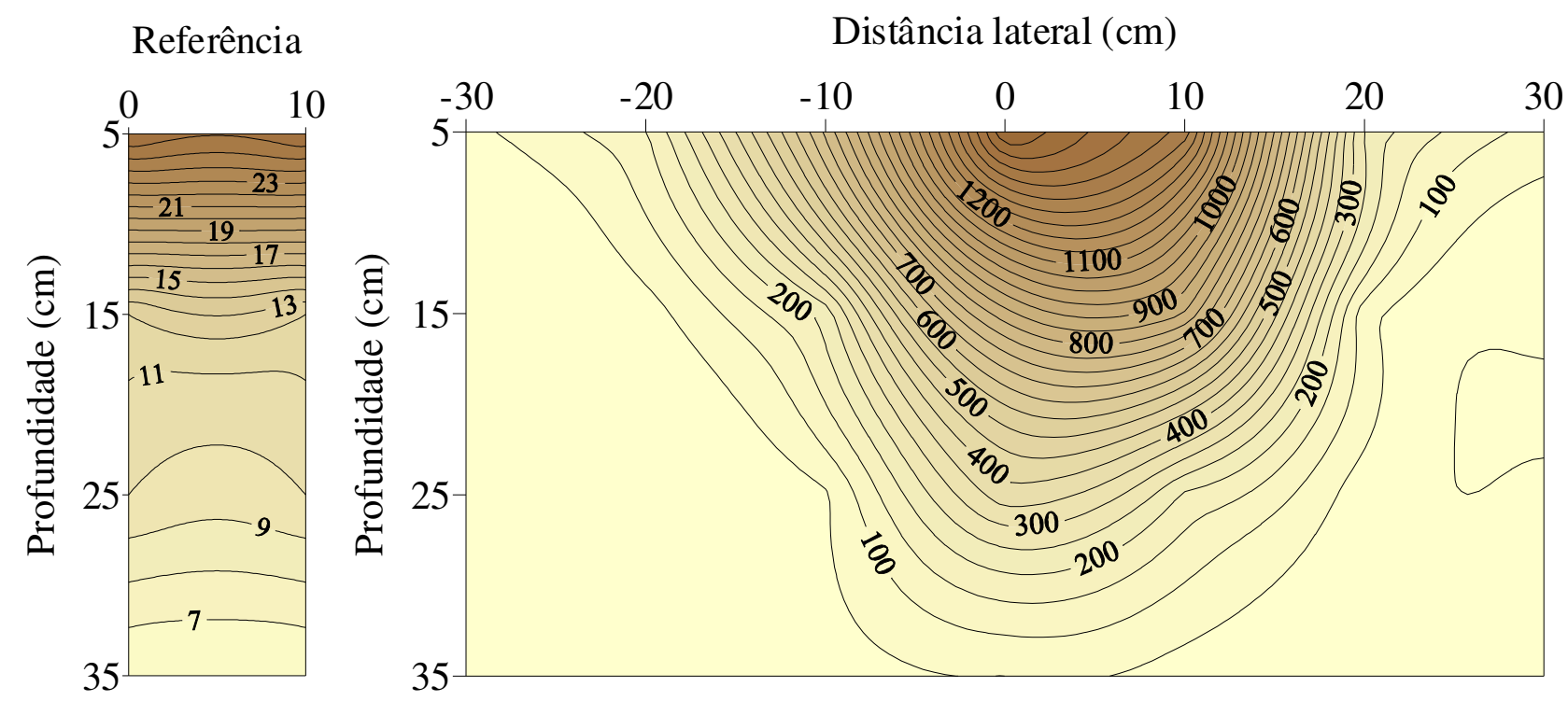

FIGURA 9. Distribuição de fósforo $\left(\mathrm{P}: \mathrm{mg} \mathrm{dm}^{-3}\right.$ ) no perfil do solo com adição de $30 \mathrm{~kg} \mathrm{ha}^{-1}$ de $\mathrm{P}_{2} \mathrm{O}_{5}\left(\mathrm{~T}_{1}\right)$ e na coluna de referência.

\section{Referência}
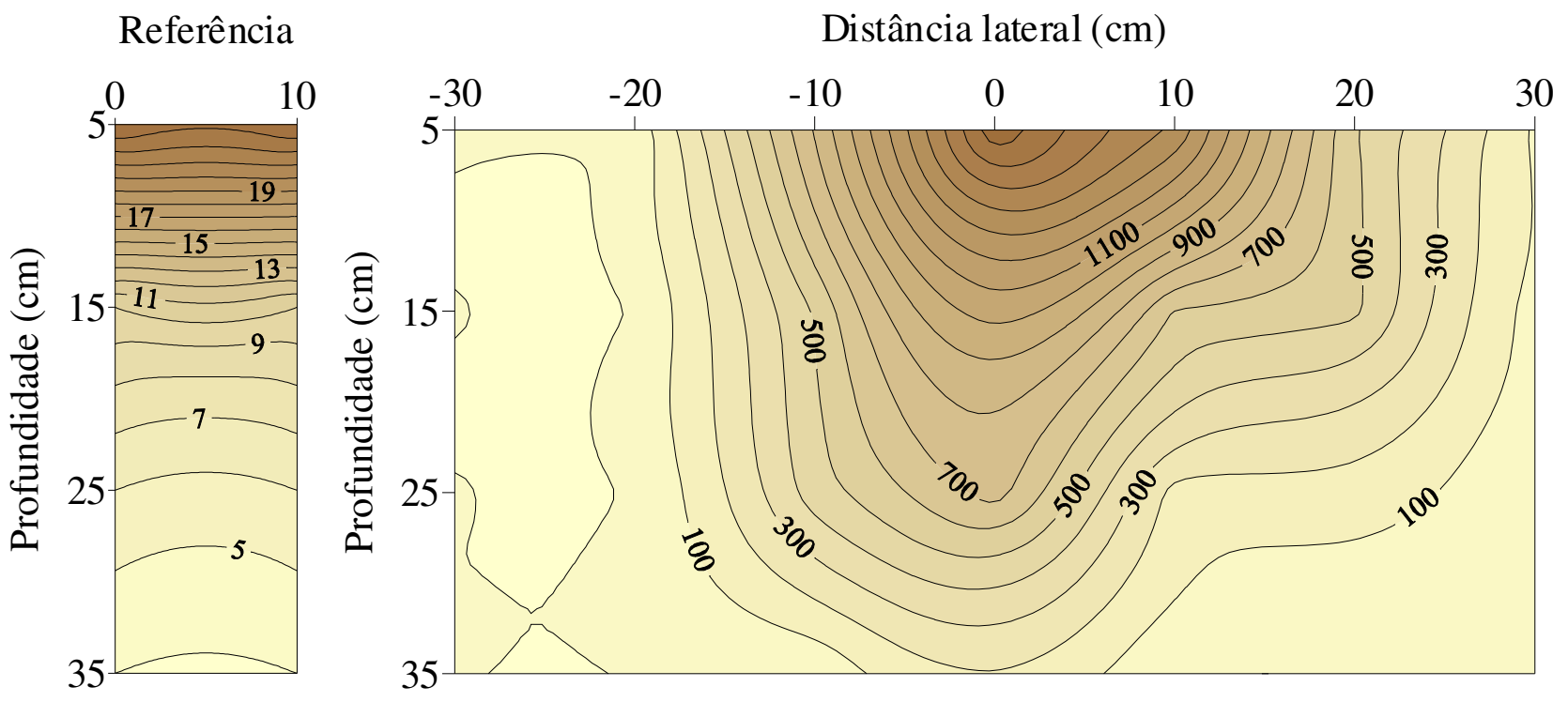

FIGURA 10.Distribuição de fósforo $\left(\mathrm{P}: \mathrm{mg} \mathrm{dm}^{-3}\right)$ no perfil do solo com adição de $60 \mathrm{~kg} \mathrm{ha}^{-1}$ de $\mathrm{P}_{2} \mathrm{O}_{5}\left(\mathrm{~T}_{2}\right)$ e na coluna de referência.

Para os tratamentos $\mathrm{T}_{3}$ e $\mathrm{T}_{4}$, verifica-se que à direta do ponto de gotejamento os teores de fósforo são maiores que os obtidos à esquerda desse ponto. Isso ocorreu devido à inclinação do 
terreno, induzindo maior caminhamento da solução na superfície do solo para a direita do ponto de gotejamento.

Os teores médios de fósforo no solo aumentaram com as doses de ácido, obtendo-se teor máximo $\left(\mathrm{P}=1.437,5 \mathrm{mg} \mathrm{dm}^{-3}\right)$ para o tratamento $\mathrm{T}_{4}(+10 \mathrm{~cm} ; 0-10 \mathrm{~cm}$ de profundidade). Esses resultados com elevados teores de fósforo concordam com BAR-YOSEF \& SHEIKHOLSMI (1976), COELHO (1994), LUDWICK (2002) e VILLAS BÔAS et al. (2002), que se referem à pouca mobilidade do fósforo no solo, sobretudo nos argilosos, devido à fixação do mesmo nas partículas de argila. $\mathrm{O}$ efeito dos tratamentos, induzindo maior caminhamento com o aumento da dose, foi também destacado por esses autores, comentando que, com irrigação localizada, há aumento da mobilidade do fósforo, devido à saturação dos sítios de adsorção, relacionando-se com a concentração no mesmo.

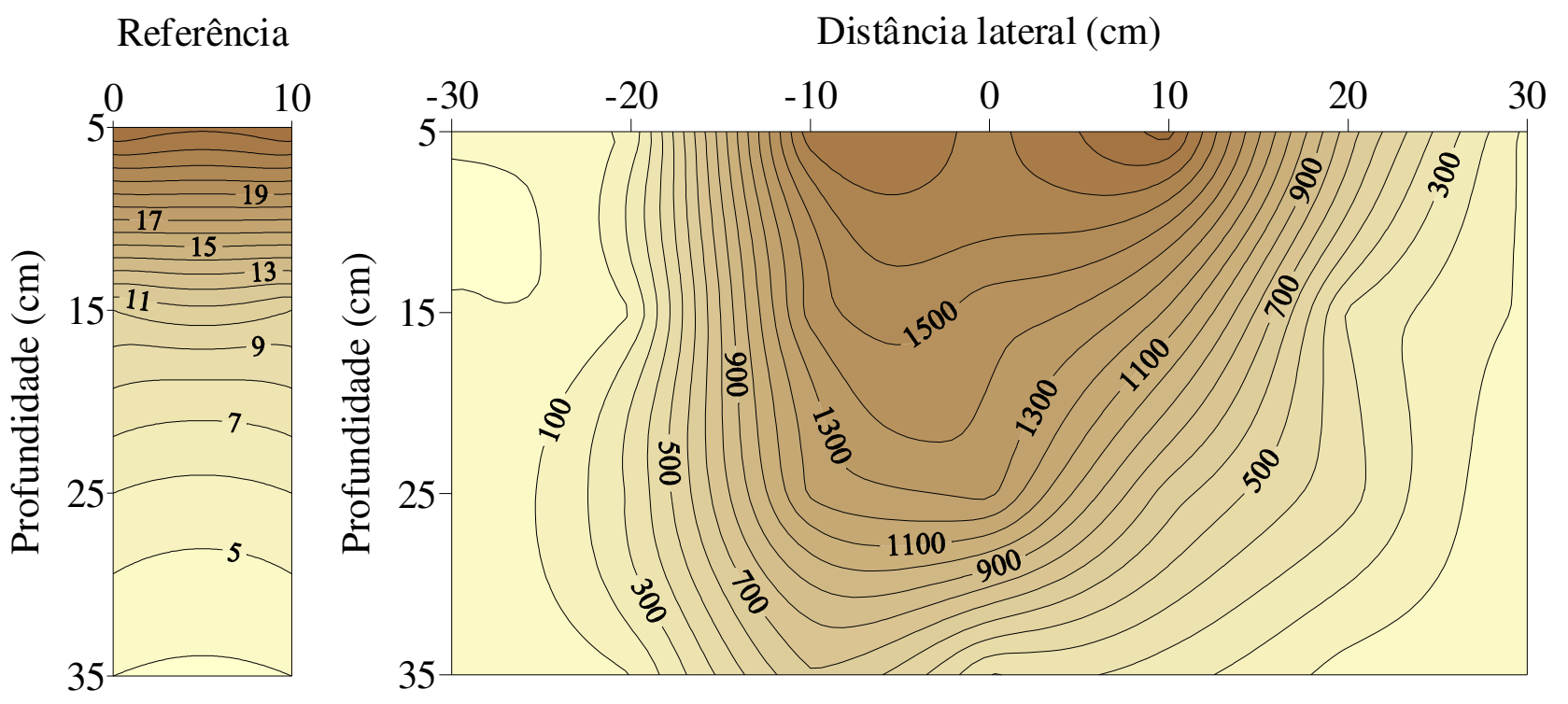

FIGURA 11.Distribuição de fósforo ( $\mathrm{P}: \mathrm{mg} \mathrm{dm}^{-3}$ ) no perfil do solo com adição de $90 \mathrm{~kg} \mathrm{ha}^{-1}$ de $\mathrm{P}_{2} \mathrm{O}_{5}\left(\mathrm{~T}_{3}\right)$ e na coluna de referência.

\section{Umidade $\mathbf{x}$ distância lateral}

Para as análises de umidade do solo, os resultados estão apresentados como médias das profundidades e das distâncias laterais, pois os gráficos de superfície, tais como apresentados para pH e teor de fósforo, não permitiram boa diferenciação de valores.

Comparando-se os valores de umidade nas distâncias laterais (Figura 13), verifica-se que o valor para a referência é de 20,5\%, enquanto, no tratamento $\mathrm{T}_{0}$, a umidade variou de 21,9 a 25,5\%. As médias mais altas concentram-se entre os $20 \mathrm{~cm}$ eqüidistantes do centro, atingindo seu pico de umidade $20 \mathrm{~cm}$ à direita do ponto de gotejamento. Para $\mathrm{T}_{1}$, os valores médios de umidade apresentam-se irregulares, pois as maiores médias estão situadas à direita do ponto de gotejamento, dos 10 aos $40 \mathrm{~cm}$, demonstrando a influência da declividade da superfície do terreno no fluxo da solução ácida no bulbo.

Semelhante ao $\mathrm{T}_{1}$, para $\mathrm{T}_{2}$ ocorreram picos de $24,5 \%$ para a umidade no ponto de gotejamento e a $20 \mathrm{~cm}$ à direita do gotejador. À esquerda, os valores são mais baixos, devido à declividade do terreno, favorecendo maior distribuição da água para o lado direito do gotejador. Para $\mathrm{T}_{3}$, foi atingido $27,3 \%$ (valor máximo) no ponto de gotejamento. Como nos tratamentos anteriores, à medida que as amostras se distanciam do ponto de gotejamento, a umidade média decresce. Para $\mathrm{T}_{4}$, a umidade dos pontos à direita do centro foi maior, levando-se a coletar amostras nesse lado até $50 \mathrm{~cm}$. 


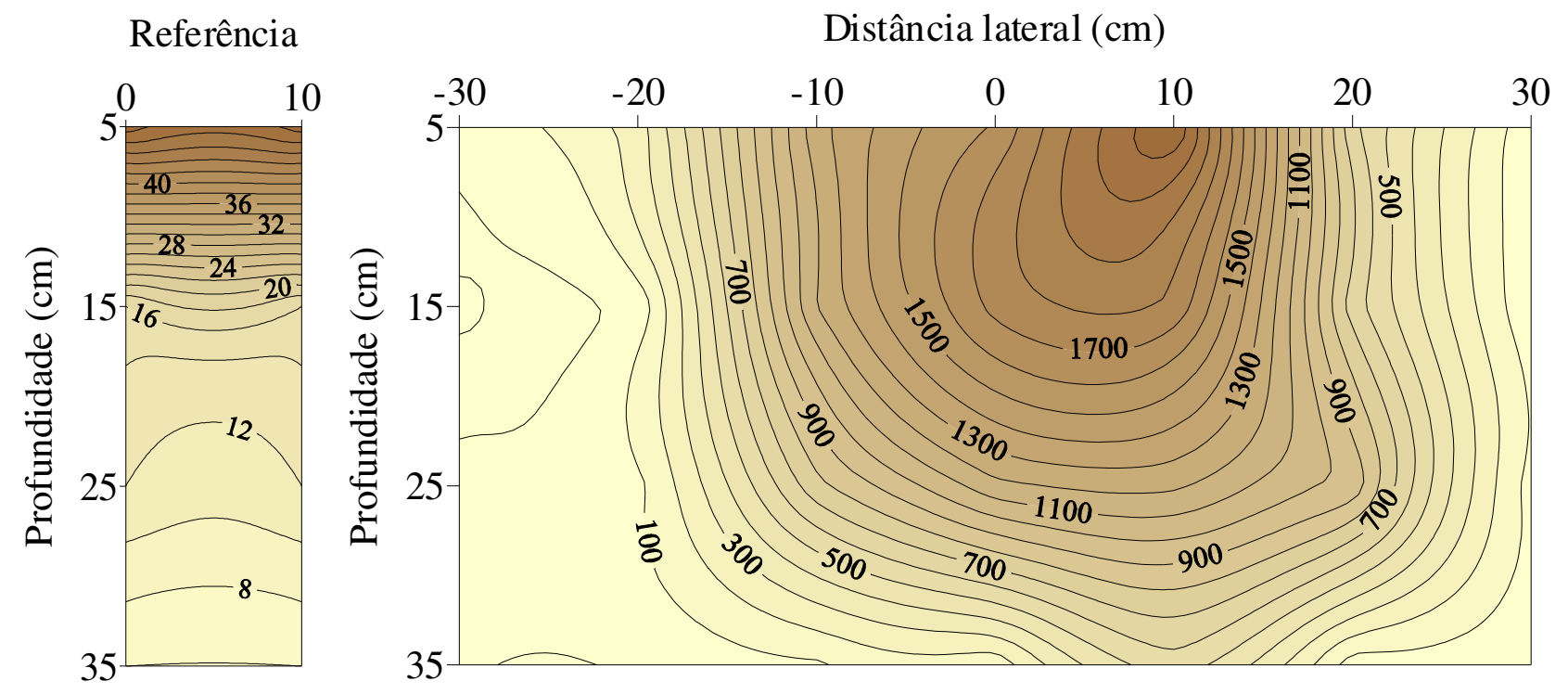

FIGURA 12. Distribuição de fósforo (P: $\mathrm{mg} \mathrm{dm}^{-3}$ ) no perfil do solo com adição de $120 \mathrm{~kg} \mathrm{ha}^{-1}$ de $\mathrm{P}_{2} \mathrm{O}_{5}\left(\mathrm{~T}_{4}\right)$ e na coluna de referência.

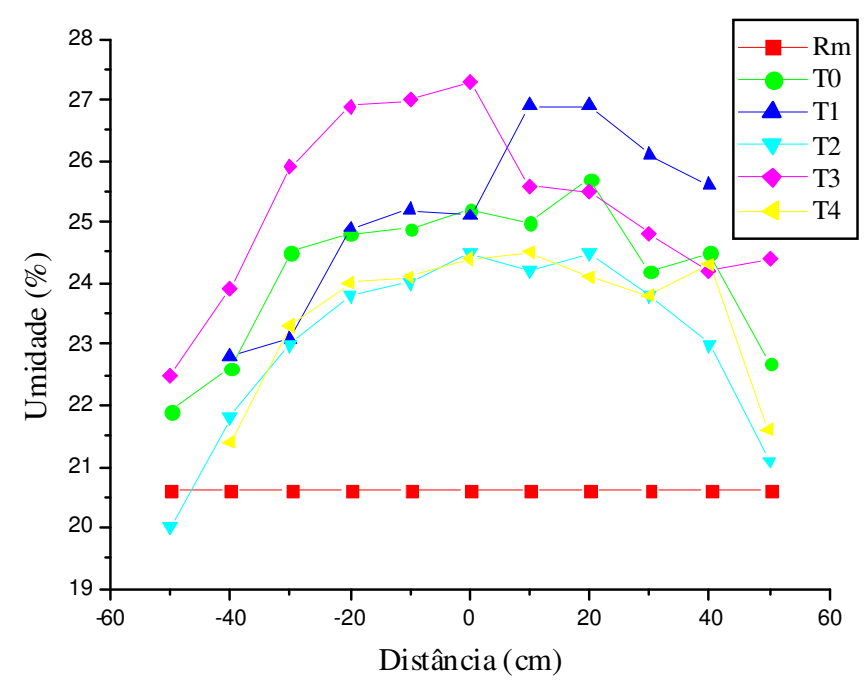

FIGURA 13. Distribuições laterais de umidade para os tratamentos e para a média da referência.

Também pela Figura 13, observa-se que a umidade média no ponto de gotejamento oscilou de 24,4 a $27,3 \%$. Uma vez que a umidade média do solo nas colunas de referência foi $20,5 \%$, o aumento máximo da umidade média provocado pelas fertirrigações foi de $6,8 \%$, semelhante $(8 \%)$ ao obtido por ZANINI (1991), que trabalhou no mesmo solo deste experimento. A expansão lateral da umidade obtida por esse autor foi de $70 \mathrm{~cm}$, pouco maior que a expansão de $50 \mathrm{~cm}$ obtida neste estudo. Também neste estudo, as maiores médias de umidade foram encontradas em torno do ponto de gotejamento e no centro do bulbo, diminuindo com o afastamento do mesmo, coerente com os obtidos por BOTREL (1988) e por ZANINI (1991), que obtiveram máxima umidade na região central do bulbo.

\section{Umidade $x$ profundidade}

Pela Figura 14, verificam-se maiores valores de umidade do tratamento $\mathrm{T}_{0}$ do que os encontrados na referência. Também, com a ação do potencial gravitacional e da evaporação da água na camada superficial do solo, a umidade na faixa de 0 a $10 \mathrm{~cm}$ foi menor que na faixa de 10 a $20 \mathrm{~cm}$, ou seja, a maior umidade no bulbo localiza-se abaixo da superfície do solo, conforme se encontra em BOTREL (1988) e ZANINI (1991). Os valores de umidade para o tratamento $\mathrm{T}_{1}$ são 
maiores que os encontrados na referência, semelhantemente ao obtido para o tratamento $\mathrm{T}_{0}$ e para os tratamentos $\mathrm{T}_{2}, \mathrm{~T}_{3}$ e $\mathrm{T}_{4}$.

Os valores médios de umidade em relação à profundidade possuem comportamento semelhante para todos os tratamentos; isso ocorreu porque o volume total aplicado de água mais ácido até o final do experimento foi o mesmo para todos eles $(80 \mathrm{~L})$. No geral, as umidades aumentaram com a profundidade, sendo $4,5 \%$ a maior diferença entre os tratamentos, na camada superficial do solo, diminuindo para $2 \%$ na camada de 40 a $50 \mathrm{~cm}$. Mesmo nas camadas mais profundas $(60-70 \mathrm{~cm})$, a umidade no interior do bulbo foi maior que a umidade original do solo (referência); como a influência do ácido fosfórico no $\mathrm{pH}$ e no teor de fósforo do solo ocorreu no máximo até a faixa de profundidade de 30 a $40 \mathrm{~cm}$, isso indica que a distribuição do fósforo no solo não seguiu o perfil de distribuição vertical da umidade.

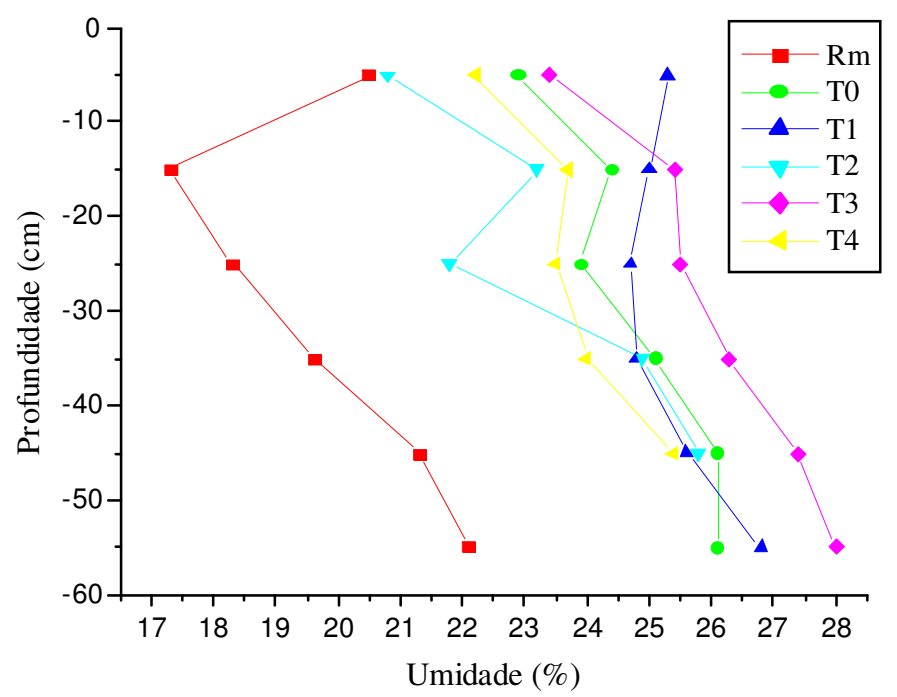

FIGURA 14. Distribuições verticais de umidade para os tratamentos e para a média das referências.

\section{CONCLUSÕES}

O ácido fosfórico aplicado em fertirrigação aumentou a acidez do solo no bulbo molhado até $30 \mathrm{~cm}$ de distância lateral e até $40 \mathrm{~cm}$ em profundidade, em relação ao ponto de gotejamento. A acidificação foi maior com o aumento da dose de ácido aplicada, atingindo $\mathrm{pH}$ de valor 3,7 para o solo que recebeu $120 \mathrm{~kg} \mathrm{ha}^{-1}$ de $\mathrm{P}_{2} \mathrm{O}_{5}$.

A expansão do fósforo no solo pela fertirrigação com ácido fosfórico atingiu a faixa de 20 a $30 \mathrm{~cm}$ de distância lateral e até $40 \mathrm{~cm}$ de profundidade, no bulbo molhado, em relação ao ponto de gotejamento, coincidindo com a região onde houve efeito no $\mathrm{pH}$. Os teores de fósforo no bulbo de gotejamento aumentaram com as doses aplicadas de $\mathrm{P}_{2} \mathrm{O}_{5}$, e os maiores teores situaram-se no ponto de gotejamento.

A influência do ácido fosfórico no pH e no teor de fósforo do solo do bulbo molhado ocorreu em menores extensões do que a atingida pela umidade; assim, a distribuição do fósforo não seguiu a distribuição de umidade no mesmo.

\section{REFERÊNCIAS}

ARGO, W.R.; BIERNBAUM, J.A. The effect of lime, irrigation-water source, and water-soluble fertilizer on root zone, $\mathrm{pH}$, electrical conductivity, macronutrient management of container root media with impatiens. Journal of American Society of Horticulture, Alexandria, v.2, n.121, p.44252, 1996.

BAR-YOSEF, B. Advances in fertigation. Advances in Agronomy, San Diego, v.65, n.1, p.1-65, 1999. 
BAR-YOSEF, B.; SHEIKHOLSMI, M.R. Distribution of water and ions in soils irrigated and fertilized from a trickle source. Soil Science Society of American Journal, Madison, v.40, n.3, p.575-82, 1976.

BOTREL, T.A. Simulação da distribuição espacial da água em solo irrigado com gotejador. 1988. 61f. Tese (Doutorado em Agronomia) - Escola Superior de Agricultura "Luiz de Queiroz", Universidade de São Paulo, Piracicaba, 1988.

BURT, C.; O'CONNOR, K.O.; RUEHR, T. Fertigation. San Luis Obispo: California Polytechnic State University, 1995. 320 p.

CABELLO, F.P. Riegos localizados de alta frecuencia. $2^{\text {nd }}$ ed. Madrid: Mundi Prensa, 1990. 417 p.

COELHO, A.M. Fertigação. In: COSTA, E.F.; VIEIRA, R.F.; VIANA, P.A. Quimigação: aplicação de produtos químicos e biológicos via irrigação. Brasília: EMBRAPA-SPI/CNPMS, 1994. p.201-27

COTE, M.C.; BRISTOW, K.L.; CHARLESWORTH, P.B.; COOK, F.J.; THORBURN, P.T. Analysis of soil wetting and solute transport in subsurface trickle irrigation. Irrigation Science, Heidelberg, v.22, n.3-4, p.143-56, 2003.

ELOI, W.M.; SOUZA, V.F. de; VIANA, T.V. de A.; ANDRADE JÚNIOR, A.S. de; HOLANDA, R.S.F. de; ALCANTARA, R.M.C.M. de. Distribuição espacial do sistema radicular da gravioleira em função de diferentes doses de nitrogênio e potássio aplicados via fertirrigação. Irriga, Botucatu, v.9, n.3, p.256-69, set-dez, 2004.

EMBRAPA. EMPRESA BRASILEIRA DE PESQUISA AGROPECUÁRIA. Sistema brasileiro de classificação de solos. Rio de Janeiro, 1999. 412 p.

FAO. FOOD AGRICULTURAL ORGANIZATION OF THE UNITED NATIONS. Riego localizado. Roma: 1986. 203 p. (Publicación, 36).

GUSTAFSON, C.D. Drip irrigation in USA. In: Irrigation Association, 1974. p.111-5. . Proceedings technical. Denver: Sprinkler

LAMM, F.R.; TROOIEN, T.P. Surface drip irrigation for corn production: a review of 10 years of research in Kansas. Irrigation Science, Heidelberg, v.22, n.3-4; p.195-200, 2003.

LI, J.; ZHANK, J.; REN, L. Water and nitrogen distribution as affected by fertigation of ammonium nitrate from a point source. Irrigation Science, Heidelberg, v.22, n.1, p.19-30, 2003.

LOGAN, T.J.; MCLEAN, E.O. Effects of phosphorus application rate soil properties, and leaching mode on P movement in soil columns. Soil Science Society American Proceedings, Madison, v.5, n.37, p.371-4, 1973.

LUDWICK, A. Principios de la fertigación. Agricultura de las Américas, New Cork, v.51, n.4, p.223, 2002.

MIRANDA, N.O.; OLIVEIRA, T.S.; MEDEIROS, J.F.; LEVIEN, S.L.A. Causas da variação em produtividade e qualidade do melão em um Latossolo Vermelho-Amarelo fertirrigado. Ciência Rural, Santa Maria, v.36, n.2, p.487-93, mar./abr. 2006.

PAPADOPOULOS, I. Nitrogen and phosphorous fertigation of tomato and eggplant. Proceedings of the HIS, Belgium, 1999. p.102-10.

RAUSCHKOLB, R.S.; ROLSTON, D.E.; MILLER, R.J.; CARLTON, A.B.; URAU, R.J. Phosphorus fertilization with drip irrigation. Soil Science Society American Journal, Madison, v.40, n.3, p.68-71, 1986.

SILVA, W.L.C.; MAROUELLI, W.A. Fertirrigação em hortaliças. ITEM, Brasília, v.52, p.45-8, dez. 2001. 
SOUZA, R.O.R.M.; BOTREL, T.A. Simulação hidráulica e avaliação de um sistema de irrigação localizada com microtubos em um pomar de cítrus. Engenharia Rural, Piracicaba, v.16, n.1, p.1-7, jul. 2005.

THORBURN, P.T.; DART, I.K.; BIGGS, I.M.; BAILLIE, C.P.; SMITH, M.A.; KEATING, B.A. The fate of nitrogen applied to sugarcane by trickle irrigation. Irrigation Science, Heidelberg, v.22, n.3-4, p.201-9, nov. 2003.

VILLAS BÔAS, R.L.; ZANINI, J.R.; DUENHAS, L.H. Uso e manejo de fertilizantes em fertirrigação. In: ZANINI, J.R.; VILLAS BÔAS, R.L.; FEITOSA FILHO, J. C. Uso e manejo da fertirrigação e hidroponia. Jaboticabal: FUNEP, 2002. p.1-25.

VILLAS BÔAS, R.L.; BÜLL, L.T.; FERNÁNDEZ, D.M.; Fertilizantes em fertirrigação. In: FOLEGATTI, M.V. (Coord.) Fertirrigação: cítrus, flores e hortaliças. Guaíra: Livraria Editora Agropecuária, 1999. p.293-319.

VIVANCOS, A.D. Fertigación. Madrid: Mundi-Prensa, 1993. 217 p.

ZANINI, J.R. Distribuição de água e do íon $\mathrm{K}^{+}$no bulbo molhado. ITEM, Brasília, n.46, 1991. p.24-38. 